\title{
OS DIREITOS DAS PESSOAS DESLOCADAS INTERNAMENTE: UMA REVISÃO DOS CONCEITOS DE CIDADANIA, SOBERANIA E ESTADO
}

\author{
Allan Victor Coelho Nascimento*
}

\begin{abstract}
RESUMO
A investigação acerca das pessoas deslocadas internamente (isto é, no interior dos seus países, mas fora dos seus espaços de vida habituais) se mostra um desafio, em virtude dos volumes de pessoas atualmente envolvidas e das condições com que se confrontam, da incapacidade (ou desinteresse) dos Estados nacionais em garantir proteção aos seus cidadãos, e do princípio de neutralidade internacional, que dificilmente permite intervenções externas no sentido da salvaguarda dos direitos humanos. Analisamos o conceito de cidadania, Estado soberano e a noção do não intervencionismo, assim como problematizamos os desafios colocados pela globalização, pela amplitude dos fenômenos migratórios e desrespeitos aos direitos humanos. Acreditamos que a análise pode servir a um maior entendimento sobre os fenômenos migratórios e fragilidade institucional, além da revisão de conceitos. Pode ainda servir para uma revisão crítica da legislação e da possibilidade de institucionalização de órgãos transnacionais de proteção.
\end{abstract}

PALAVRAS-CHAVES: Pessoas Deslocadas Internamente, cidadania, soberania, Estado, intervencionismo, direitos humanos.

\begin{abstract}
Research on internally displaced persons (i.e. those living inside their own countries but outside their usual areas of settlement) is a challenge, due to the large number of people involved, the harsh conditions they face, the inability (or lack of interest) of national states to protect their citizens, and the international neutrality principle by which any external intervention aimed at safeguarding human rights becomes a difficult issue. The concept of citizenship,
\end{abstract}

Especialização em Migrações, Inter-Etnicidades e Transnacionalismo pela Universidade Nova de Lisboa (2008). 
sovereign State and the notion of non-interventionism are also examined, as well as analysing the challenges of globalization, scale of migratory phenomena and disrespect for human rights. We believe the analysis can serve a greater understanding of migratory phenomena and institutional weakness, beyond the review of concepts. It can also be used for a critical review of the legislation and the possibility of transnational rights bodies institutionalization.

KEYWORDS: Internally Displaced People, human rights, sovereignty, citizenship, interventionism, State

\section{INTRODUÇÃO}

Inúmeras pessoas, por diversas razões, são obrigadas a deslocarem-se de seus lugares habituais de residência. Algumas não chegam a atravessar qualquer fronteira. Frequentemente, perdem suas referências sociais, sejam os amigos, os vizinhos ou suas famílias; e vêem-se desamparadas por seus Estados que não garantem sua proteção e por vezes as perseguem, e por instrumentos jurídicos internacionais desfasados e insuficientes que as renegam pelo fato de não cruzarem as fronteiras de seu país.

A análise das novas dinâmicas migratórias que caracterizam as últimas décadas bem como sua pluralidade de causas evidenciam a importância da temática das Pessoas Deslocadas Internamente (PDI) para a agenda de Estados, ONG, organismos internacionais e instituições transnacionais. Através da investigação sobre esse crescente fluxo migratório, os deslocados dentro das fronteiras nacionais, tenciona-se perceber como a falta de uniformização de procedimentos das instituições a quem cabe sua proteção dificulta seu censo e o estabelecimento de padrões e instrumentos jurídicos, além de possibilitar sua suscetibilidade a ficar desamparados.

Para além da vigência do princípio da não intervenção, consequência da manutenção da concepção de soberania dos Estados, a falta de um reconhecimento internacional do conceito de PDI, e a consequente inexistência de um agente a quem caiba sua proteção, traduz-se em uma grande dificuldade no estabelecimento de um verdadeiro amparo aos deslocados internos. Formalmente, a legislação internacional referente aos direitos humanos por si só garantiria a proteção às PDI; porém, seu incumprimento mostra-se 
bastante comum no que se refere a deslocados internos. Ao invés de gerar desânimo, essa deficiência pode servir para impulsionar a comunidade internacional a criar, desenvolver ou remodelar instituições que regulem e fiscalizem os processos de prevenção, proteção, assistência e criação de soluções duradouras.

Em 1998, os Princípios Orientadores Relativos aos Deslocados Internos (PORDI ${ }^{1}$ foram lançados pelo então Representante Especial do Secretário-Geral das Nações Unidas para os Deslocados Internos, Francis Deng. Esses Princípios devem orientar os governos e as agências humanitárias e de desenvolvimento internacional na proteção, na identificação de garantias e direitos, na assistência e na proteção durante a deslocação, o retorno, a reinstalação e a reintegração. Os PORDI não têm força vinculativa, apesar de surgirem da carência de jurisdição internacional referente às PDI, comungarem com os direitos humanos internacionalmente reconhecidos e serem análogos aos direitos dos refugiados.

Os PORDI definem o termo PDI como:

"[...]pessoas, ou grupos de pessoas, forçadas ou obrigadas a fugir ou abandonar as suas casas ou seus locais de residência habituais, particularmente em consequência de, ou com vista a evitar, os efeitos dos conflitos armados, situações de violência generalizada, violações dos direitos humanos ou calamidades humanas ou naturais, e que não tenham atravessado uma fronteira internacionalmente reconhecida de um Estado." (ONU, 2001: 01)

\section{GLOBALIZAÇÃO}

Vivemos em um mundo globalizado, mas ainda formalmente organizado em função da premissa da inviolabilidade soberana dos Estados nacionais. Várias organizações internacionais denunciam o anacronismo da situação, admitindo que os Estados que hoje temos, e que resultam da modernidade, dificilmente acomodam a multitude de desafios colocados pela "globalização". Essa perspectiva é sustentada por Evans (2007) quando diz que o crescimento intenso das transações econômicas que atravessam as fronteiras nacionais

1 Princípios Orientadores relativos aos Deslocados Internos, Nova Iorque: Organização das Nações Unidas, 2001. 
reduziu o poder do Estado, marginalizando-o como um ator econômico. $\mathrm{O}$ crescente fluxo que ultrapassa as fronteiras nacionais seja de pessoas, financeiro, comercial, ideias, dentre outros, é assumido por uma estrutura organizativa além da nacional, um alicerce transnacional.

Held (1999) procura definir o que é o processo de globalização, e o vê como:

"Um processo (ou um conjunto de processos) que incorpora a transformação da organização espacial das relações e das transacções sociais - medida em termos de extensão, intensidade, velocidade e impacto -, gerando fluxos e redes de actividade, de interacção e de exercício de poder transcontinentais ou inter-regionais." (Held et al. 1999, 16 in Castles, 2002: 132)

Segundo Marchueta (2002), o Estado necessita descobrir uma nova definição de sua função para uma nova sociedade, visto que vêse afetado no próprio cerne das suas competências e legitimidade. E há quem fale da emergência de uma "esfera pública transnacional" (Fraser, 2005) $)^{2}$.

Por outro lado, houve nas últimas décadas uma retomada de Estados desenvolvimentistas (na América Latina e Leste Asiático), contrapondo-se a regimes reguladores, conduzidos apenas pela racionalidade dos mercados e pela concorrência econômica. O

\footnotetext{
${ }^{2}$ Sassen refere-se aos desafios teóricos e metodológicos trazidos pelos processos transnacionais como a globalização econômica, política e cultural, às ciências sociais: "[...] a globalização é mais que a noção comum da interdependência crescente do mundo em geral, e da formação de instituições globais. Todavia, se o global, como afirmo, habita parcialmente o nacional, torna-se evidente que a globalização em suas muitas formas envolve duas premissas básicas das ciências sociais. A primeira é uma premissa explícita ou implícita sobre o Estado-nação como o contentor de processos sociais. A segunda é a correspondência implicada do território nacional com o nacional - a premissa de que, se um processo ou condição se localiza em uma instituição nacional ou no território nacional, ele deve ser nacional. Ambas premissas descrevem condições que existiram, ainda que nunca totalmente, durante grande parte da história do Estado moderno, especialmente desde a Primeira Guerra Mundial e, até um certo nível, continuam a existir atualmente. O que é diferente hoje em dia é que essas condições estão sendo parcial, mas ativamente, desarticuladas. Diferente também é o nível dessa desarticulação." (Sassen, 2010: 09)
} 
Estado, desta forma, preocupa-se não apenas com o bem-estar social, mas também debruça-se sobre políticas industriais, considerando o poder estratégico da indústria nacional e a competitividade internacional da nação. No Brasil e em outros países sul-americanos, com a crise das políticas neoliberais, a partir dos anos de 1990, partidos ou coalizões de esquerda passam a vencer eleições, promovendo políticas caracterizadas por um maior ativismo do Estado, buscando não apenas o crescimento econômico, mas uma maior distribuição de renda e diminuição das desigualdades. Ressurgindo o debate sobre desenvolvimentismo, das relações entre sociedade e Estado e também das relações entre Estados.

Desta forma, torna-se relevante a discussão de conceitos como cidadania, soberania e Estado, tendo em vista que a evolução desses conceitos nem sempre anda junto. Marshall (1950), após Segunda Guerra Mundial, problematiza o conceito de cidadania (e sua evolução) com a ampliação dos direitos humanos. É dessa época, por exemplo, a construção dos Estados-Providência - mas também a Convenção das Nações Unidas de 1951 relativa ao Estatuto dos Refugiados. Da mesma maneira, Turner (1990), estudando a década de 1970, observa a evolução do conceito e das práticas de cidadania através da visibilidade de movimentos sociais que atuam além das fronteiras nacionais. Habermas $(1991,2003)$ traz a discussão da transformação estrutural da esfera pública; em seu entender, o papel do Estado e da sociedade civil passa a ser contestados por outros atores, questionando-se, mais tarde, a possibilidade da institucionalização de uma esfera pública além da nacional. Neste sentido os conceitos de soberania e de Estado também merecem maior atenção, assim como sua ressignificação. Trazendo esse debate aos direitos das Pessoas Deslocadas Internamente, em 1998 são redigidos os Princípios Orientadores Relativos aos Deslocados Internos, buscando suprir uma carência de legislação internacional sobre uma questão de garantia de direitos humanos que radica na jurisprudência dos Estados nacionais soberanos. Importante salientar que o conceito de cidadania perpetua sua dinamicidade, ao contemplar, ainda, outros debates, como o direito de grupos minoritários, direitos culturais, sexuais, de imigrantes e estrangeiros.

Cardoso e Faletto (2004) oferecem uma interpretação às possibilidades de desenvolvimento da América Latina, além das 
ideias e debates sobre desenvolvimento econômico até a década de 1960: de consolidação e modernização do Estado impulsionando a acumulação de capitais, traçando metas de crescimento e condições especiais à uma política de desenvolvimento econômico eficiente; e, transformação mais radical nas sociedades e nos sistemas econômicos. Para os autores os projetos de desenvolvimento econômico correntes nesses países não se referiam à realidade do período, não havendo possibilidades das economias dos países latino-americanos se desenvolverem de forma independente desvinculada das economias ditas desenvolvidas. Pereira (2011), de forma critica (e marxista), classifica essas formulações como uma interpretação weberiana da Teoria da Dependência:

"A esfera política ganha centralidade na obra de Cardoso e Faletto,
pois é uma mediação central para a dominação de uma classe sobre a
outra, ou seja, a política é tida como uma forma de dominação social,
mediação fundamental para estabelecer novas bases econômicas de
desenvolvimento. Em outras palavras, para os autores a política é a
forma de um determinado grupo social impor um modo de produção
e acumulação a todo o conjunto da sociedade. Assim, uma
dominação política efetiva, capaz de desenvolver a América Latina
sobre a única saída possível (dependência e associação), para os
autores, situa-se na reorganização política e social dos grupos
internos e em sua articulação com os grupos do centro capitalista.
Esta é a chave para o desenvolvimento econômico da América
Latina para Cardoso e Faletto." (Pereira, 2011: 04)

Entretanto trata-se de uma questão da maior importância hoje em dia: como podem as forças de desenvolvimento nacional (coligação de forças movidas pelo interesse geral/nacional - por exemplo, a criação de empregos, preservação do ambiente, direitos sociais, etc.) contrariar as forças e dinâmicas globais movidas por interesses particulares (deslocalização de empregos, liberalização do setor financeiro, etc.)?

Os conceitos de cidadania, soberania e Estado nem sempre evoluem e acompanham a emergência de novos direitos, dependendo, por exemplo, do controle estatal que é exercido sobre a população e o acompanhamento que fazem dela. No caso das PDI, pode-se dizer que o Estado demitiu-se de suas funções? Considerar 
que com o processo de globalização, os Estados perderam seu controle de ação, que suas barreiras e limitações foram ultrapassadas por essa sucessão sistemática de mudanças, não seria um discurso simplista e limitado? Por mais que os conceitos tenham evoluído desde o Tratado de Vestfália do século XVII e haja perda da onipotência do Estado soberano, também não presenciamos um momento de Estado desaparecido. As transformações e evoluções dos conceitos são lentas e assumindo posições extremistas, pode-se cair numa polarização de natureza puramente ideológica.

O surgimento de novos instrumentos internacionais de proteção, de blocos econômicos, aparatos jurídicos internacionais como o Tribunal Penal Internacional, são contemporâneos da proliferação de novos países soberanos e o amadurecimento de movimentos separatistas, assim como, da intensificação de regionalismos. Destacamos, ainda, as contradições das invasões uni ou bilaterais (por parte dos EUA e de seus aliados) do Afeganistão (2001) e Iraque (2003), com a condenação e interferência da violação do direito de não intervencionismo no conflito entre Ucrânia e Rússia (2014).

A proteção das PDI e a garantia dos seus direitos humanos, seja a nível nacional ou transnacional, ainda esbarra em interesses de ordem econômica, financeira, e ainda, étnicos ou religiosos. Além disso, a fragilidade das instituições, sejam elas locais, nacionais ou internacionais, torna-se uma aliada à não garantia de proteção à essas pessoas.

\section{CIDADANIA}

Na metade do século XX, Marshall publica um célebre texto intitulado "Citizenship and social class", vindo a marcar a discussão da época sobre cidadania. O que o autor pretende mostrar, basicamente, é que os direitos de cidadania vão evoluindo e tornando-se mais complexos à medida que as sociedades políticas (europeias) se tornam mais inclusivas. Assim, o estabelecimento dos direitos de cidadania civil é o reconhecimento da igualdade formal (cidadãos) entre indivíduos na prática desiguais (classes sociais, gênero, etc.), os direitos políticos consagram o direito à mobilização em torno da expressão de interesses e pontos de vista diversos dos cidadãos (independentemente dos títulos de nobreza, da riqueza, 
etc.), e os direitos sociais visam corrigir desigualdades de acesso aos direitos civis e políticos. Turner expõe as fragilidades do pensamento de Marshall (etnocentrismo e teleologismo), mas parte dele para defender, por exemplo, o reconhecimento dos direitos culturais, ambientais, sexuais, religiosos, etc., enquanto expressão de forças que são mais amplas e complexas que as identificadas em 1950 (no após-guerra) por Marshall. O texto de Turner tem um mérito algo semelhante (embora de menor impacto) ao de Marshall, justamente ao abrir a discussão para esta nova "geração" de direitos que se começam a constituir como objeto de lutas ideológicas e políticas a partir dos anos 70 (talvez até antes) e que se intensificam à medida que ganham amplitude transnacional - com os movimentos antiguerra, de defesa do ambiente, dentre outros.

Turner (1990) diz, ainda, que o debate ou esboço sobre uma teoria de cidadania vai além do acesso às instituições educacionais, serviços de saúde ou equipamentos comunitários. Para o autor, são mais relevantes as condições de integração e solidariedade social. Ao contrário da visão etnocêntrica de Marshall, Turner salienta que há diferentes caminhos à cidadania de acordo com as tradições culturais de cada país. Desta forma, o autor determina diferentes tradições de cidadania de acordo com dois eixos analíticos: de baixo para cima (ação revolucionária) ou de cima para baixo (o Estado com a iniciativa da mudança, garantindo os direitos paulatinamente); e dicotomia público-privado (cidadania pode ser adquirida dentro do espaço público, pela conquista do Estado, ou no espaço privado, através da afirmação dos direitos individuais, podendo ser sustentados por organizações que constituem barreiras à ação do Estado).

Questiona-se o conceito de cidadania, já que a relação com a nacionalidade passa a não fazer tanto sentido no mundo atual. A diversidade étnica e cultural vem atenuar essa situação, seja no sentido de expansão de direitos além dos critérios de nacionalidade, bem como o reforço de identidades a nível local.

Tomas Hammar (1990) cunha o conceito de "denizen" (por referência a citizen) nos anos 1990 para tipificar essa situação no caso dos imigrantes: não são cidadãos nacionais, mas são-lhes reconhecidos os direitos dos cidadãos - exceto os direitos políticos.

Castles (2005) quando se debruça sobre a análise do crescimento das comunidades transnacionais tornando-se necessária 
a transformação dos enquadramentos institucionais, de modo a corresponder às novas formas de identidade social e sobre a revisão do modelo de cidadania baseada em uma nacionalidade única e exclusiva de um Estado-nação, conclui:

"O crescimento das comunidades transnacionais pode levar, em longo prazo, a repensar os próprios conteúdos da cidadania. De modo a dar conta dos diversos tipos de relações estabelecidas pelos transmigrantes $^{3}$ com Estados diferentes, podem vir a ser necessárias formas diferenciadas de pertença, tais como direitos políticos num Estado, direitos económicos noutro e direitos culturais num terceiro (Bauböck 1994; Bauböck e Rundell, 1998). Na prática isto já acontece, quando os Estados que acolhem imigrantes criam formas de «quasicidadania» ou de cidadania confinada ${ }^{4}$ (Hammar, 1990), garantindo direitos relacionados com a residência, com o emprego ou com a segurança social a grupos específicos de imigrantes. No entanto, estas práticas foram sendo desenvolvidas sem cuidar de conferir uma coerência global e sem ter em consideração as suas consequências para a cidadania em longo prazo." (Castles, 2005: 91-92)

Joppke (2007) quando problematiza a complexidade das abordagens sobre cidadania, se refere às diferentes dimensões de cidadania e seus diferentes significados para cada grupo ou pessoa, e ainda destaca os direitos como um dos aspectos fundamentais da cidadania. Para o autor com a diversificação étnica novos direitos tornam-se primordiais como os direitos de anti-discriminação e reconhecimento multicultural. Os valores sociais centrais (em uma sociedade multicultural) são: tolerância, em vez de solidariedade, e imparcialidade em vez de igualdade. A "boa sociedade" é a sociedade que permite a coexistência pacífica das divergências. Joppke destaca, ainda: a extensão dos direitos de cidadania para não-

3 Segundo o próprio autor: "O termo transmigrante pode ser utilizado para identificar pessoas cuja existência é moldada através da participação em comunidades transnacionais estribadas na imigração. Nina Glick-Schiller sustenta que «as pessoas que vivem as suas vidas cruzando fronteiras, desenvolvendo redes sociais, familiares, políticas, económicas e religiosas que as incorporam em dois ou mais estados podem ser considerados como transmigrantes» (Glick-Schiller 1999, 203)." (Castles, 2005: 81)

${ }^{4}$ Denizenship, no original (N. do T.). 
cidadãos, como por exemplo a contribuição com base em benefícios, tais como o desemprego, indenizações e pensões, direitos trabalhistas e civis; e, a criação ou o reforço dos direitos das minorias: os Estados liberais têm apenas, excepcionalmente, praticado políticas explícitas de reconhecer grupos minoritários, principalmente, em uma tentativa de corrigir injustiças históricas, como a escravatura, o colonialismo e a repressão das minorias nacionais, sendo que o reconhecimento é assimétrico já que seria impossível reconhecer todos os grupos. O Brasil, desde os primeiros anos do Governo Lula (2003-2010), vem adotando políticas de ações afirmativas (também chamadas de políticas de discriminação positiva), pela organização e pressão do movimento negro, onde beneficia brasileiros de origem africana no ingresso às universidades públicas ou empregos públicos.

Para Cardoso (2002) cidadania abrange, desde o século XX, uma dimensão social e implicaria também, hoje, uma dimensão cultural, no sentido de um direito à cultura. Joppke (2007) também destaca a evolução do termo cidadania antes usado apenas na relação Estado/nacionalidade, hoje transpassando para questões sexuais, ecológicas e multiculturais:

"Vários estados europeus receptores de comunidades não-nacionais
começaram nas últimas décadas do século passado a ser cada vez
mais confrontados com a necessidade de proceder a uma
desnacionalização da sua cidadania, de forma a torná-la num
conceito dependente já não da nacionalidade mas da inalienável
condição humana do indivíduo, condição por via da qual se justifica
também o direito à integridade cultural e social das entidades
comunitárias em que aquele se insere." (Carvalhais, 2006: 05)

Bosniak (2001) alerta que a cidadania é tanto uma ideia como um conjunto de instituições e práticas sociais, e uma estratégia para sua discussão vai além de problematizar se a cidadania está se movendo para além dos Estados-nação, mas também que nós estamos nos movendo para além de uma cidadania.

Para Aleinikoff (1998) cidadania é uma característica universal e distintiva do panorama político moderno, os Estados definiriam formalmente seus cidadãos, estabelecendo suas obrigações e direitos, ao mesmo tempo em que também definiriam quem são seus nãocidadãos. Se por um lado o autor diz que os cidadãos teriam seus 
direitos básicos e oportunidades garantidos por esse Estado, reconhece a complexidade e proliferação de grupos de não-cidadãos residindo nesses Estados (por exemplo: residentes, visitantes, migrantes sem autorização e estrangeiros buscando entrada).

Entretanto, no que diz respeito ao cumprimento dos direitos humanos, direitos de grupos minoritários, os Estados nem sempre os garantem. Muitas vezes por serem eles mesmos os agentes perseguidores e que desrespeitam, e em outros casos por não conseguirem controlar grupos beligerantes internos. Para Bauböck (1994) a aplicação clara dos direitos humanos necessita de instrumentos fortes, de leis internacionais e do judiciário internacional. Na estrutura política global tais instituições são atualmente localizadas a nível continental e da comunidade internacional de Estados. Os membros dessa comunidade são Estados, não mulheres e homens individuais. Mas se Estados não fornecem a garantia dos direitos humanos básicos, as instituições dessa comunidade internacional podem assumir a responsabilidade. Mas o autor lembra que a aplicação dos direitos humanos por organismos internacionais não deve ser vista como um movimento em direção da "cidadania global", mas poderia ser caracterizada como a busca por uma "polity of polities" que atribui um membro político substituto para aqueles que foram privados de todos os seus direitos enquanto membros de determinados Estados. No entanto, termos como cidadania global, cidadania transnacional, formas pósnacionais de cidadania vêm surgindo no discurso sobre a relativização do conceito de cidadania (Soysal, 1999; Bosniak, 2001; Carvalhais, 2006, inter alia).

Tonet (2005), em uma análise marxista, contesta um sistema em que um trabalhador assalariado explorado pode ser considerado um cidadão:

"A teoria liberal da cidadania (Kant, Hobbes, Locke, Rousseau e outros) tem como pressuposto que todos os homens são iguais e livres por natureza. As desigualdades sociais seriam apenas o desdobramento da igualdade e da liberdade naturais. A busca da realização pessoal, uma exigência da liberdade e da igualdade naturais, teria dado origem a toda sorte de conflitos que, na ausência de qualquer elemento inibidor, poderiam pôr em perigo a sobrevivência da própria humanidade. Por isso mesmo, os homens 
ter-se-iam visto obrigados a se organizar em sociedade e a instituir uma autoridade (Estado) capaz de garantir a observância de certos limites. Deste modo, a desigualdade social é considerada legítima e constitutiva do mundo humano. Tratava-se, pois, não de suprimi-la, o que seria impossível, mas apenas de coibir os seus excessos. [...] Neste sentido, todos os homens já eram potencialmente cidadãos. [... A] cidadania seria sempre vista como um instrumento para equilibrar as desigualdades sociais e não para erradicá-las." (Tonet, 2005: 472)

Para Johnston (2001) o movimento trabalhista sozinho pode ser apreendido como um movimento de cidadania.

As Pessoas Deslocadas Internamente, por serem grupos marginalizados, perseguidos (muitas vezes pelo próprio Estado), reforçam a necessidade da revisão de conceitos como a de cidadania. A discussão sobre o termo cidadania vai além da supressão da ideia de direitos relativos à nacionalidade, visto que as PDI são, na grande maioria das vezes, nacionais. A ideia de uma cidadania transnacional pode ser pautada também na possibilidade de movimentos sociais transnacionais, agências de proteção internacionais dos direitos humanos, estabelecerem um papel protagonista na discussão e ação junto aos Estados da proteção dessas pessoas.

Soysal (1999) estabelece quatro questões que implicam na revisão e discussão de conceitos como cidadania, esfera pública, identidade e direitos:

"As transformações nacionais existentes e composições étnicas dos países europeus, como uma consequência da massiva migração, fluxos não apenas da periferia européia, mas também de terras distantes; a intensificação crescente do discurso transnacional e instrumentos legais que sistematizam os direitos humanos ou personificam como um princípio a nível mundial. A elaboração de direitos individuais faz expandir novas formas de reivindicações como as de: mulheres, crianças, minorias, imigrantes, etc.; identidade coletiva tem sido redefinida como uma categoria dos direitos humanos. A identidade tem se tornado uma importante ferramenta organizacional e simbólica para criar novos grupos de solidariedade e mobilizar recursos (ex. movimentos das mulheres, ambientalistas, gays e lésbicas, identidades e interesses regionais, indígenas, imigrantes...); a difusão da soberania e a emergência de políticas multi-níveis, tal como nós observamos com o gradual 
desdobramento da União Européia. A difusão e partilha da soberania entre instituições políticas locais, nacionais e transnacionais, permitindo novos actores, abrindo-se um leque de novas estratégias organizacionais, e a competição por recursos e definições." (Soysal, 1999: 05)

\section{SOBERANIA}

O conceito de soberania surge no século XVI, com o filósofo francês Jean Bodin, com o objetivo de legitimar o poder absoluto do rei, e também de impedir o caos social causado por desordem, conflitos de interesses ou guerras religiosas ${ }^{5}$. Thomas Hobbes busca igualmente justificar o contexto político do absolutismo. No pacto social firmado entre o Estado e os indivíduos, os últimos perderiam suas liberdades e poderes individuais em troca de segurança no convívio social ${ }^{6}$. Locke e Rousseau acreditavam em um consentimento consciente dos governados. A confirmação do poder soberano viria da vontade da maioria dos indivíduos, não se tratando de um poder soberano de origem divina, absoluto, arbitrário e impositivo $^{7}$ (Ferrer, 2003).

${ }^{5}$ Entretanto para Bodin haveria limitações ao poder soberano, uma limitação pela lei natural (ao mesmo tempo em que não esclarece essa noção): "É portanto lícito desobedecer às ordens do soberano que prescrevam actos indubitavelmente contrários (Bodin não explica a forma de decidir) à lei natural, embora a revolta continue interdita." Ao mesmo tempo em um tom contraditório diz: "Com efeito, «a mais dura tirania» é preferível à anarquia." (Touchard, 1970: 61)

${ }^{6}$ Definição de Thomas Hobbes de Estado: "Uma pessoa de cujos actos uma grande multidão, mediante pactos recíprocos uns com os outros, foi instituída por cada um como autora, de modo a ela poder usar a força e os recursos de todos da maneira que considerar conveniente, para assegurar a paz e a defesa comum. Àquele que é portador dessa pessoa chama-se soberano, e dele se diz que possui poder soberano.

Todos os restantes são súbditos." (Hobbes, 1999: 146)

7 "Assim, pela natureza do pacto, todo o acto de soberania, que o mesmo é dizer, todo acto autêntico da vontade geral, obriga ou confere direitos igualmente a todos os cidadãos, de forma que o soberano conhece apenas o corpo da nação e não distingue nenhum dos que a compõem. Que é então, propriamente, um acto de soberania? Não é uma convenção entre um superior e um subordinado, mas sim uma convenção do corpo com cada um dos seus membros: convenção legítima, porque tem como base o contrato social; equitativa, porque é comum a todos; útil, porque não pode ter outro objectivo que não seja o bem comum; e, sólida, porque tem por garantia a força pública e o poder supremo." (Rousseau, 1974: 37) 
Castles (2005) lembra ainda que ao longo de sua evolução histórica, os Estados-nação ocidentais expandiram-se, destruindo a soberania de outros Estados através de conquistas e da colonização. Desta forma o princípio do respeito pela soberania não se aplicava a Estados não-ocidentais. A democracia e a propriedade nos países do Ocidente assentavam na repressão, na exploração e no racismo nas colônias. Skocpol (1985) lembra que não é apenas o governo que indica o grau de autonomia de um Estado, mas também suas orientações internacionais, manutenção das funções domésticas, e organização de suas próprias políticas.

Tanto Hegel (1990) como Touchard (1970b) acentuam que a legitimidade do Estado passa pelo reconhecimento dos outros Estados, devendo deste modo respeitar os contratos, pois neles se fundam as obrigações de uns para com os outros. Hegel prevê ainda o desaparecimento desse Estado, seja pela violência, guerras ou ação de um grande homem - nesta altura Hegel não pensa que o herói possa ser um ser coletivo, o proletariado por exemplo.

$O$ conceito de soberania vem desde então se transformando lentamente com os acontecimentos históricos; todavia as últimas décadas presenciaram mudanças radicais no que diz respeito aos direitos humanos, ao conceito de fronteira, aos processos de globalização e particularmente no que respeita aos fluxos migratórios, assim questionando os elementos constitutivos dos Estados em fundamentos essenciais como o poder soberano ${ }^{8}$.

\footnotetext{
8 "A um nível mais geral, desde o final do século XX, todos os Estados-nação têm sido afectados por processos de globalização, caracterizados pelo rápido aumento de fluxos transfronteiriços de todos os tipos e pela formação de redes transnacionais nas esferas económicas, cultural, política e social (Castells 1996; Castells 1997; Held et al. 1999; Hoogvelt 1997). A globalização ameaça corroer as principais características do Estado-nação. 1 - A soberania vê-se reduzida pelo direito internacional e pelos princípios dos direitos humanos que legitimam a intervenção da «comunidade internacional» no interior dos Estados (como aconteceu na antiga Juguslávia). 2 - A autonomia encontra-se limitada pelo poder das grandes empresas transnacionais e pela actuação dos organismos transnacionais, o que reduz a capacidade do Estado para tomar e levar por diante decisões de índole económica, política e social. 3 - O controle fronteiriço vê-se ameaçado pelos crescentes fluxos de capital, mercadorias, de migrantes, e factores ambientais e de ideias. 4 - A democracia vê-se restringida se os parlamentos eleitos pela população deixarem de ser responsáveis pelas decisões importantes, transitadas para a esfera supranacional, onde não existe representação popular. 5 - $\mathrm{O}$ elo fundamental entre cidadania e
} 
Soberania garantida em instrumentos internacionais através do princípio da não ingerência e do não intervencionismo em assuntos internos, ora abalada pela proliferação de ordenamentos transnacionais.

Apesar do florescimento de organizações transnacionais dando resposta a um novo contexto político, social, estratégico, financeiro e tecnológico e na busca por preencher lacunas deixadas pelos Estados nacionais acerca das questões ambientais, direitos do homem entre outros, presencia-se nas últimas décadas do século $\mathrm{XX}$ e início do século XXI, a proliferação de novos Estados.

Forjaz (2000) nega que o reforço de identidades sociais, culturais e políticas a nível local, e o enfraquecimento das estruturas políticas nacionais e identidades construídas em nível nacional poderiam enfraquecer a consolidação de uma esfera pública transnacional capaz de responder às omissões estatais. Para a autora, seja internamente ou externamente, os Estados nacionais vêm sendo pressionados pelas forças da globalização. Enquanto a construção do Estado envolveu a subordinação de poderes infra e supranacionais, vivemos hoje o processo inverso de subordinação do Estado por esses poderes.

\section{ESTADO / INSTITUIÇÕES}

A situação das PDI relaciona-se diretamente com essa ineficácia estatal em protegê-las, ao mesmo tempo em que a ingerência internacional vê-se limitada em uma atuação que depende do próprio Estado opressor ou ineficaz. Porém questionamos os interesses dos principais atores da política internacional, que, ao intervirem, legitimam o poder soberano em casos de Estados que não assumem a responsabilidade de proteção que lhes caberia. Ao mesmo tempo que, quando ultrapassa-se o princípio do não intervencionismo, como nas guerras do Iraque e da Bósnia, há

nacionalidade encontra-se ameaçado: onde quer que existam populações diversas com grande mobilidade e formas de afiliação ancoradas em mais do que um Estado, deixará de existir «um espaço para cada raça». 6 - Os Estados-providência entram em declínio à medida que os mercados internacionais e as grandes empresas transnacionais vão ganhando poder para restringir a capacidade de intervenção dos governos e para exigir a liberalização e a privatização." (Castles, 2005: 103-104) 
interesses políticos, econômicos e estratégicos sobrepostos à ideia de garantia e respeito aos direitos humanos dos cidadãos.

Acreditamos que não havendo a discussão e elaboração de novos conceitos de cidadania e soberania, nem regularidade na proteção das pessoas, as intervenções militares, como as citadas acima, continuarão existindo, sem contribuir, efetivamente, à resolução do problema.

Enquanto para alguns defensores dos direitos humanos, há perda da soberania estatal a partir do momento que um Estado persegue seus nacionais ou não pode protegê-los, para Regis (2006) a intervenção humanitária não abalaria o princípio da soberania. Para o autor, essa intervenção externa pode ser promovida por organizações internacionais, ou, até mesmo, por organizações regionais e, em último caso, por intervenções unilaterais, promovidas por países membros da comunidade internacional, contribuindo para reforçar os Estados afetados.

O Alto Comissário das Nações Unidas para Refugiados, António Guterres, reforça a possibilidade de intervenção continental ao afirmar em Kampala ${ }^{9}$ que "o acordo ${ }^{10}$ representa na prática o conceito de «responsabilidade de proteger». Demonstra que a soberania nacional é plenamente compatível com a responsabilidade de proteger". E acrescentou que a convenção serve como lembrete de que a responsabilidade de proteger seus próprios cidadãos é primeiramente dos Estados e que, quando esse falhar, há uma

${ }^{9}$ Cimeira Especial dos Chefes de Estado e de Governo da União Africana sobre Refugiados, Repatriados e Deslocados Internos em África, ocorrida em Kampala em outubro de 2009.

${ }^{10}$ A Convenção sobre a Proteção e Assistência às Pessoas Deslocadas Internamente em África, ocorreu em 2009, na cidade de Kampala (Uganda) e foi a primeira convenção regional que abordou de forma abrangente a deslocação interna, incluindo prevenção, resposta e soluções sustentáveis. Buscando proteger os direitos de pessoas deslocadas em resultado de catástrofes naturais, conflito armado, violência generalizada, violação de direitos humanos e projetos de desenvolvimento. A Convenção reiterou a legislação internacional e da União Africana existente, incluindo normas de direitos humanos e de direito humanitário internacionais. Ao reforçar e reunir essas normas num só instrumento, ofereceu um enquadramento legal único dirigido às especificidades da deslocação interna no continente africano, apresentando uma base jurídica mais clara e mais sólida para a proteção de PDI (IDMC, 2010). 
responsabilidade coletiva africana de agir (Fleming e Hassan, 2009).

Apesar de a Carta das Nações Unidas (1945) determinar o respeito dos Estados pela soberania dos outros, seu Capítulo VII diz:

"O Conselho de Segurança determinará a existência de qualquer ameaça à paz, ruptura da paz ou acto de agressão e fará recomendações ou decidirá que medidas deverão ser tomadas [...]", e ainda "[...] poderá levar a efeito, por meio de forças aéreas, navais ou terrestres, a acção que julgar necessária para manter ou restabelecer a paz e a segurança internacionais. Tal acção poderá compreender demonstrações, bloqueios e outras operações, por parte das forças aéreas, navais ou terrestres dos membros das Nações Unidas". (ONU, 1945: 09-11)

Porém, na atual ordem política mundial, os regimes violadores dos direitos do homem não são tratados do mesmo modo pelos principais atores da comunidade internacional, como recorda Lopes (2008). O que reforça a necessidade da instituição de conceitos amplamente aceitos e do fortalecimento de entidades transnacionais capazes de atuar apenas em prol dos direitos humanos.

Para Lopes (2008), além de as intervenções terem que ser clara e inequivocamente decididas pelo Conselho de Segurança da ONU, têm que respeitar requisitos legais; não é apenas por ações militares que a intervenção pode ser efetivada. Sanções econômicas; campanhas na mídia; pressões econômicas, políticas e sociais; corte de relações diplomáticas; ingerência judiciária; seriam alternativas.

Assim como as ações militares, as outras opções descritas por Lopes devem ser devidamente estudadas e adaptadas às diferentes realidades para que não atinjam essencialmente a população já vulnerável ${ }^{11}$.

${ }^{11}$ Portes (2006; 2008; 2008b) e Krawczyk (2003) em seus estudos sobre instituições
e desenvolvimento, especialmente na América Latina, chamam a atenção para a
ineficácia da imposição de modelos de desenvolvimento e de instituições sobre os
países pobres ou em desenvolvimento. Os autores destacam a importância de se
conhecer não apenas os fenômenos sociais, mas sim as articulações que têm, devido
as dimensões que não são quantificáveis claramente (questões culturais, ideológicas,
axiológicas). Neste sentido Evans (1995), diz que os resultados de desenvolvimento
dependem tanto do caráter geral das estruturas do Estado como dos papéis que o 


\section{CONSIDERAÇÕES FINAIS}

Saskia Sassen em "Expulsions" (2014) assume que a política econômica global depara-se com uma nova lógica de expulsão. Para Sassen, uma análise além das fronteiras nacionais dos atuais processos e fenômenos que geram expulsões torna-se fundamental ao seu entendimento. As dinâmicas e interesses econômicos não se restringem às fronteiras dos Estados, assim como sua visibilidade é global. Sua premissa reforça as ideias centrais de nosso artigo, a proliferação das razões que levam a deslocação compulsória interna faz as PDI estarem presentes nas agendas dos Estados onde vivem (e das reivindicações de movimentos sociais locais, regionais, nacionais e transnacionais), dos Estados vizinhos (que temem que se transformem em refugiadas) e dos organismos internacionais (sejam institucionalizados ou de denúncia, e ainda estejam presentes ou ausentes nos países onde há deslocamento). Os "expulsos" de Sassen são muitas vezes PDI. Suas análises, mais uma vez, consolidam argumentos deste estudo, especialmente os relacionados com a ressignificação de conceitos que acreditamos ultrapassados.

Acreditamos ser ingênuo admitir que um sistema que preza a eficiência, a concorrência e o "cada um por si", possa ser flexível o suficiente para garantir os direitos das PDI. Não afirmamos aqui que somente uma mudança revolucionária estenda todos os direitos a essas pessoas, no entanto a revisão de conceitos, internacionalmente e anacronicamente aceitos, como os de cidadania, esfera pública e soberania, seria fundamental.

Neste trabalho questionamos conceitos consagrados há séculos e que na maioria das vezes não mais respondem às transformações sociais contemporâneas, seja de fluxos migratórios ou garantia dos direitos humanos. Esses conceitos exigem, na atualidade, uma discussão ultrapassando a mera reflexão sobre as funções do Estado.

Estado persegue, desta forma, o sucesso das transformações e mudanças dependeriam da reconstrução dos laços entre sociedade e Estado. 


\section{REFERÊNCIAS BIBLIOGRÁFICAS}

ALEINIKOFF, Thomas Alexander; MARTIN, David A; MOTOMURA, Hiroshi (1998), Immigration and Citizenship: Process and Policy. Saint Paul: West Group.

BAUBÖCK, Rainer (1994), Transnational Citizenship: Membership and Rights in International Migration. Hants: Edward Elgar Publishing Limited. BOSNIAK, Linda (2001), "Desnationalizing Citizenship", in Alexander Aleinikoff; Douglas Klusmeyer, Citizenship today: global perspectives and practices. Washington: Brookings Institution Press, 237-252.

CARDOSO, Fernando Henrique; FALETTO, Enzo (2004), Dependência e desenvolvimento na América Latina. Rio de Janeiro: Civilização Brasileira.

CARDOSO, João Casqueira (2002), "Cidadania", in Rui Leandro Maia, Dicionário de Sociologia. Porto: Porto Editora, Lda, 52-53.

CARVALHAIS, Isabel Estrada (2006), "Condição Pós-Nacional da Cidadania Política. Pensar a integração de residentes não-nacionais em Portugal". SOCIOLOGIA, PROBLEMAS E PRÁTICAS, 50, 109-130.

CASTLES, Stephen (2002), "Estudar as Transformações Sociais". SOCIOLOGIA, PROBLEMAS E PRÁTICAS, 40, 123-148.

(2005), Globalização, transnacionalismo e novos fluxos migratórios: Dos trabalhadores convidados às migrações globais. Lisboa: Fim de Século.

EVANS, Peter (1995), Embedded Autonomy: States and Industrial Transformation. Princeton: Princeton University Press.

. (2007), Instituciones y desarrollo en la era de la globalización neoliberal. Bogotá: Colección En Clave de Sur.

FERRER, Walkiria; SILVA Jacqueline (2003), A Soberania segundo os Clássicos e a crise conceitual na atualidade. Revista de Direito, Universidade de Marília, vol.3.

FLEMING, Melissa; HASSAN, Yusuf (2009), "União Africana adota convenção para proteger e assistir deslocados internos". Página consultada a 29 de março 2017. http://www.acnur.org/t3/portugues/noticias/noticia/uniao-africana-adotaconvencao-para-proteger-e-assistir-deslocadosinternos/?L=type $=100 ?$ tx_acnurgooglecs_pi $1 \% 5 \mathrm{Bgcs}$ q $\% 5 \mathrm{D}=$ costa.

FORJAZ, Maria Cecília (2000), "Globalização e Crise do Estado Nacional”. RAE - Revista de Administração de Empresas, 40 (2), 38-50. 
FRASER, Nancy (2005), "Transnationalizing the Public Sphere". Página $\begin{array}{llllll}\text { consultada } & \text { a } & 29 & \text { de } & \end{array}$ http://www.republicart.net/disc/publicum/fraser01_en.htm.

HABERMAS, Jürgen (1991), The Structural Transformation of the Public Sphere: An Inquiry Into a Category of Bourgeois Society. Cambridge: MIT Press.

(2003), Mudança estrutural da Esfera Pública: investigações quanto a uma categoria da sociedade burguesa. Rio de Janeiro: Tempo Brasileiro.

HAMMAR, Tomas (1990), Democracy and the Nation State: Aliens, Denizens, and Citizens in a World of International Migration: Gower Pub Co.

HEGEL, Georg (1990), Princípios da Filosofia do Direito. Lisboa: Guimarães Editores, Lda.

HOBBES, Thomas (1999), Leviatã ou matéria, forma e poder de um Estado Eclesiástico e Civil. Lisboa: Imprensa Nacional - Casa da Moeda.

IDMC (2010), "A Convenção de Kampala ao serviço das PDIs: Guia para a sociedade civil sobre o apoio da ratificação e implementação da Convenção sobre a Protecção e Assistência às Pessoas Deslocadas Internamente em África". Página consultada a 29 de março de 2017. http://www.internaldisplacement.org/assets/publications/2010/2010-making-the-kampalaconvention-work-thematic-pt.pdf

JOHNSTON, Paul (2001), "The Emergence of Transnational Citizenship among Mexican Immigrants in California", in Alexander Aleinikoff; Douglas Klusmeyer, Citizenship today: global perspectives and practices. Washington: Brookings Institution Press, 253-277.

JOPPKE, Christian (2007), "Transformation of Citizenship: Status, Rights, Identity”. Citizenship Studies, 11 (1), 37-48.

KRAUCZYK Nora Rut; WANDERLEY, Luiz Eduardo (orgs.), (2003), América Latina: Estado e reformas numa perspectiva comparada. São Paulo: Cortez Editora.

LOPES, Domingos (2008), Direitos Humanos em questão. Dever de ingerência humanitária? Porto: Campo das Letras.

MARCHUETA, Maria Regina (2002), O Conceito de Fronteira, na Época da Mundialização. Lisboa: Instituto da Defesa Nacional.

MARSHALL, T. H. (1950), Citizenship and social class and other essays. Cambridge University Press. 
NASCIMENTO, Allan (2010), "PDI - Pessoas Deslocadas Internamente: Retorno e Reinserção Social favorecendo o desenvolvimento". Anais da $1^{a}$ Conferência em prol do Desenvolvimento das Províncias de Benguela e Kuanza-Sul: Universidade Katyavala Bwila.

. (2011), "PESSOAS DESLOCADAS INTERNAMENTE. Da actuação do Estado soberano à intervenção da comunidade internacional". SOCIOLOGIA, PROBLEMAS E PRÁTICAS, 66: 117-134.

. (2011b), "Demolições e desalojamentos forçados em Luanda (Angola) e perda de terra pelos agricultores familiares em Santarém (Brasil) vistos por uma ótica comparativa". Anais do XI Congresso Luso Afro Brasileiro de Ciências Sociais: Universidade Federal da Bahia.

ONU (1945), Carta das Nações Unidas. São Francisco: Organização das Nações Unidas.

. (1951), Convenção de 1951 relativa ao Estatuto dos Refugiados. Genebra: Organização das Nações Unidas.

- (2001), Princípios Orientadores relativos aos Deslocados Internos. Nova Iorque: Organização das Nações Unidas.

PEREIRA, Gênesis de Oliveira (2011), "A Teoria da Interdependência e do Desenvolvimento Associado: as posições de Cardoso e Faletto". Anais do Colóquio Nacional Marx e o Marxismo 2011: teoria e prática. Núcleo Interdisciplinar de Estudos e Pesquisas sobre Marx e o Marxismo: Universidade Federal Fluminense. Página consultada a 29 de março de 2017.

http://www.uff.br/niepmarxmarxismo/MManteriores/MM2011/TrabalhosP DF/AMC32F.pdf.

PORTES, Alejandro (2006), "Institutions and Development: A Conceptual Re-Analysis". Population and Development Review, 32 (2), 233-262.

Reflections. Princeton: Princeton University.

PORTES, Alejandro; SMITH, Lori D (2008b), "Institutions and Development in Latin America: A Comparative Analysis". St Comp IntDev, 43, 101-128.

REGIS, André (2006), "Intervenções Humanitárias, soberania e a emergência da Responsabilidade de Proteger no Direito Internacional Humanitário". Prima Facie - Revista eletrônica do Programa de PósGraduação em Ciências Jurídicas - CCJ/UFPB, 9 (5), 5-17.

ROUSSEAU, Jean-Jacques (1974), O Contrato Social. Mem Martins: Publicações Europa-América. 
SASSEN, Saskia (2010), Sociologia da Globalização. Porto Alegre: Editora Artmed.

-. (2014), Expulsions: Brutality and Complexity in the Global Economy. Cambridge: Havard University Press.

SKOCPOL, Theda (1985), "Bringing the State Back In: Strategies of Analysis in Current Research", in Peter B. Evans; Dietrich Rueschemeyer; Theda Skocpol, Bringing the State Back In. Cambridge: Cambridge University Press, 03-38.

SOYSAL, Yasemin Soysal (1999), Identity, rights, and claims-making: Changing dynamics of citizenship in postwar Europe. Lisboa: FCSH/UNL Faculdade de Ciências Sociais e Humanas - Universidade Nova de Lisboa.

TONET, Ivo (2005), "Educar para a cidadania ou para a liberdade?". PERSPECTIVA, 23(2), 469-484.

TOUCHARD, Jean (1970), História das Ideias Políticas 3. Lisboa: Publicações Europa-América.

TURNER, Bryan S. (1990), "Outline of a Theory of Citizenship". SAGE Social Science Collections, 24(2), 189-217. 